\title{
Role of Dopamine in the Primate Caudate Nucleus in Reward Modulation of Saccades
}

\author{
Kae Nakamura and Okihide Hikosaka \\ Laboratory of Sensorimotor Research, National Eye Institute, National Institutes of Health, Bethesda, Maryland 20892-4435
}

\begin{abstract}
Expected reward impacts behavior and neuronal activity in brain areas involved in sensorimotor processes. However, where and how reward signals affect sensorimotor signals is unclear. Here, we show evidence that reward-dependent modulation of behavior depends on normal dopamine transmission in the striatum. Monkeys performed a visually guided saccade task in which expected reward gain was different depending on the position of the target. Saccadic reaction times were reliably shorter on large-reward trials than on smallreward trials. When position-reward contingency was switched, the reaction time difference changed rapidly. Injecting dopamine $\mathrm{D}_{1}$ antagonist into the caudate significantly attenuated the reward-dependent saccadic reaction time changes. Conversely, injecting $\mathrm{D}_{2}$ antagonist into the same region enhanced the reward-dependent changes. These results suggest that reward-dependent changes in saccadic eye movements depend partly on dopaminergic modulation of neuronal activity in the caudate nucleus.
\end{abstract}

Key words: basal ganglia; caudate; saccade; dopamine; reward; primate

\section{Introduction}

Primate (Inoue et al., 1985; Watanabe, 1996; Leon and Shadlen, 1999; Platt and Glimcher, 1999; Amador et al., 2000; Liu et al., 2000; Stuphorn et al., 2000; Glimcher, 2001; Kobayashi et al., 2002; Shidara and Richmond, 2002; Schultz et al., 2003; Roesch and Olson, 2004; Sugrue et al., 2004) and human (for review, see McClure et al., 2004) studies have shown that neuronal activity in many brain areas is modulated by expected reward. These changes impact motor behavior, as measured by changes in choice or movement speed. However, it is unclear which neural pathways are crucially involved in incorporating reward information with sensorimotor or cognitive signals.

The dopamine system has been implicated in reward-related functions. Dopamine neurons respond to the delivery of unexpected reward and to sensory cues that predict reward (Ljungberg et al., 1991; Schultz, 1998; Satoh et al., 2003; Kawagoe et al., 2004). Reward-seeking behaviors and reward-related incentive learning can be impaired by dopamine antagonists (Beninger and Miller, 1998; Wise, 2004). At the cellular level, dopamine exerts powerful modulatory influences on intrinsic membrane properties and synaptic efficacy of the striatal projection neurons via $\mathrm{D}_{1^{-}}$and $\mathrm{D}_{2}$-like receptor activation (Calabresi et al., 1987; Nicola et al., 2000; Reynolds and Wickens, 2002; Mahon et al., 2004).

It has been suggested that reward-dependent modulation of

Received Nov. 10, 2005; revised March 30, 2006; accepted April 3, 2006.

This work was supported by the intramural research program of the National Eye Institute.

We thank Drs. Matt Roesch, Masaki Isoda, Long Ding, Hiroyuki Nakahara, Robert H. Wurtz, and Barry J. Richmond for helpful comments. We also appreciate GCAmerica, Inc. for providing us with dental acrylic, which was indispensable for our surgery.

Correspondence should be addressed to Kae Nakamura, Laboratory of Sensorimotor Research, National Eye Institute, National Institutes of Health, Building 49, Room 2A50, 49 Convent Drive, Bethesda, MD 20892-4435. E-mail: kae@|sr.nei.nih.gov.

DOl:10.1523/JNEUROSCI.4853-05.2006

Copyright $\odot 2006$ Society for Neuroscience $\quad$ 0270-6474/06/265360-10\$15.00/0 neuronal activity might occur in the striatum, an input channel of the basal ganglia, and that dopamine may be responsible for this process. Anatomically, the striatum receives convergent inputs from many cortical areas that carry sensorimotor/cognitive signals (Selemon and Goldman-Rakic, 1985; Parthasarathy et al., 1992) as well as strong dopaminergic projection from the substantia nigra pars compacta (Lynd-Balta and Haber, 1994). The striatum is involved in making associations between particular stimuli and behavioral responses, the process of which initially depends on reward signals but eventually may become more habitual (Packard and Knowlton, 2002; White and McDonald, 2002; Gerdeman et al., 2003; Everitt and Robbins, 2005). However, it is still unclear how dopamine alters neuronal activity in the striatum, and in turn, how these changes impact behavior. Here, we address this issue by using the primate saccade system, taking advantage of its measurable motor output and its relatively well understood neuronal circuitry (Hikosaka et al., 2000).

When different reward sizes are associated with particular locations of saccade targets, visual, saccadic, and cognitive signals carried by single neurons in the oculomotor region in the caudate nucleus are strongly modulated by expected reward (Kawagoe et al., 1998; Lauwereyns et al., 2002a,b; Watanabe et al., 2003). The neuronal activity in the caudate nucleus impacts behavior via pathways through the substantia nigra pars reticulata (Sato and Hikosaka, 2002) and the superior colliculus (Ikeda and Hikosaka, 2003) and is strongly correlated with changes in the saccadic reaction time (Takikawa et al., 2002b; Itoh et al., 2003).

To test the hypothesis that the reward-dependent modulation of saccades is dependent on dopamine-induced changes in caudate neuronal activity, we blocked dopamine receptor by injecting dopamine $\mathrm{D}_{1}$ or $\mathrm{D}_{2}$ antagonist locally into the oculomotor regions in the caudate. We found that local blockade of dopamine receptors in the caudate significantly changed the rewarddependent modulation of reaction times. 


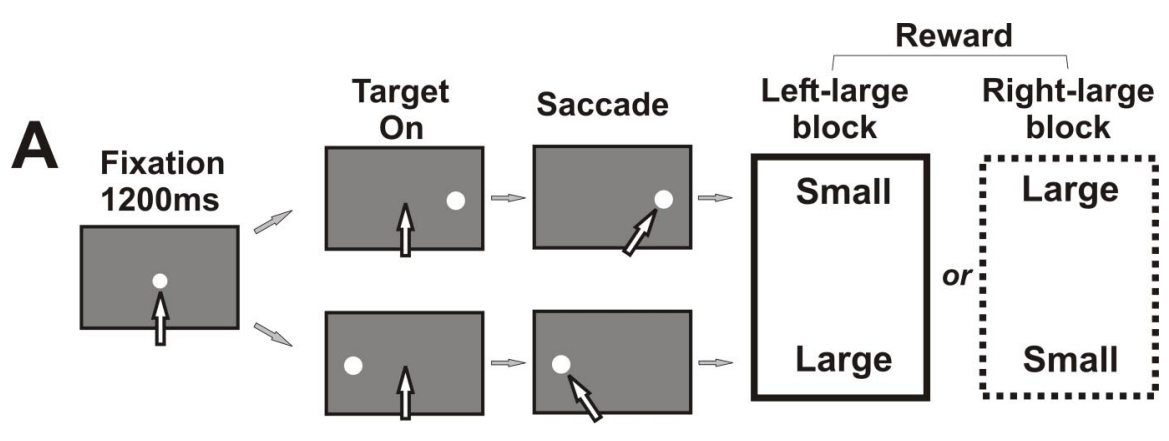

B

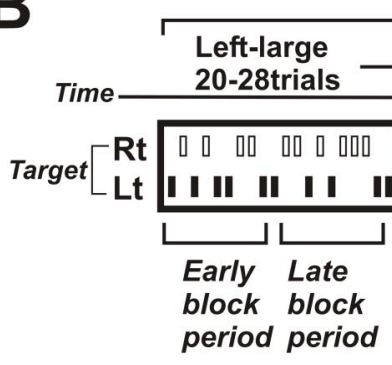

One session

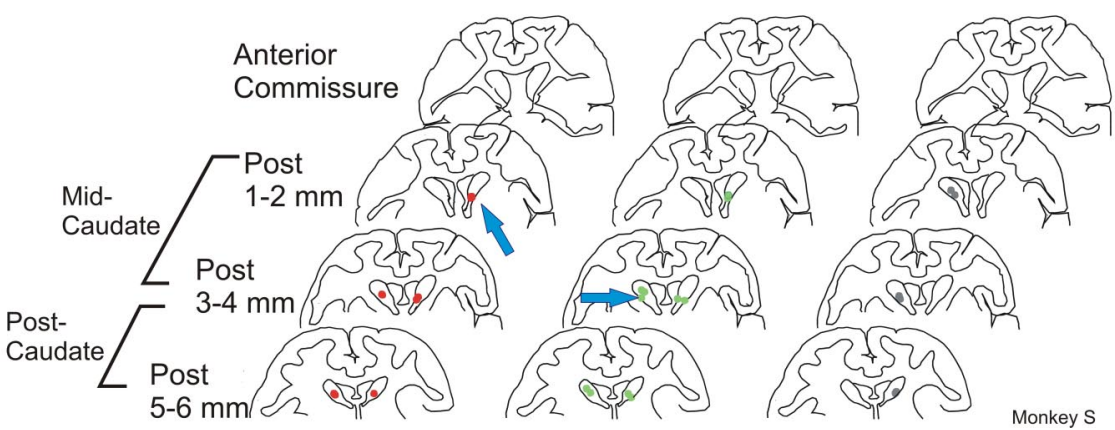

Figure 1. Visually guided saccade task with position-dependent reward difference. The white arrows indicate the direction of the gaze. $A$, After $1200 \mathrm{~ms}$ of fixation on the central fixation point, the target came on either on the left or right, and the monkey had to make a saccade to the target. In left-large condition, left saccades were followed by large reward, whereas right saccades were followed by small reward; in right-large condition, the position-reward contingency was reversed. $\boldsymbol{B}$, Left-large and right-large conditions were alternated every $20-28$ trials as blocks. The location of the target was determined pseudo-randomly. For later analysis, trials within a block were divided into early and later block periods. One session of experiment consists of four to six blocks. Rt, Right; Lt, left. C, Injection sites of D antagonist (SCH23390), D antagonist (Eticlopride), and saline are mapped on coronal magnetic resonance images posterior to the anterior commissure with $2 \mathrm{~mm}$ intervals (monkey S). Based on the drug effects, we divided the injection sites into two parts: midcaudate, 1-4 mm posterior to the anterior commissure and postcaudate, 5- $6 \mathrm{~mm}$ posterior to the anterior commissure. The arrows indicate the examples shown in Figures $2, A$ and $B$ (for $\mathrm{D}_{1}$ antagonist), and $5, A$ and $B$ (for $D_{2}$ antagonist).

\section{Materials and Methods}

General. We used four hemispheres of two adult female rhesus monkeys (Macaca mulatta; laboratory designations, S and L). Both animals had been implanted with scleral search coils for measuring eye position and a post for holding the head. The recording chambers were placed over the fronto-parietal cortices. All procedures were approved by the Institute Animal Care and Use Committee and complied with Public Health Service Policy on the humane care and use of laboratory animals.

All aspects of the behavioral experiment, including presentation of stimuli, monitoring of eye movements, monitoring of neuronal activity, and delivery of reward, were under the control of a QNX-based real-time experimentation data acquisition system (REX). Eye position was monitored by means of a scleral search coil system with $1 \mathrm{~ms}$ resolution. Stimuli generated by an active matrix liquid crystal display projector (PJ550; ViewSonic, Walnut, CA) were rear-projected on a frontoparallel screen $25 \mathrm{~cm}$ from the monkey's eyes. Drops of water or juice were delivered as reward through a spigot under control of a solenoid valve after successful completion of each trial.

Behavioral task. The main task was a visually guided saccade task with position-biased rewards. Essential procedure of the task is summarized in Figure 1, $A$ and $B$. Each trial began with presentation of a central fixation point $\left(0.5^{\circ}\right)$. After the animal maintained fixation on the spot for $1200 \mathrm{~ms}$, the fixation point was turned off, and a target, a white small $\operatorname{dot}\left(1.2^{\circ}\right)$, appeared at either right or left, $20^{\circ}$ from the fixation point, to which the animal was required to make a saccade. There was no time gap between turning off of the fixation point and target onset, except for five experiments (four midcaudate and one postcaudate injections of $\mathrm{D}_{1}$ antagonist) in which there was a 100 ms gap. The effects were similar except that reaction times were shorter in the gap-present condition than in the gap-absent condition (supplemental Tables 1-1, 1-2, available at www. jneurosci.org as supplemental material). After $100 \mathrm{~ms}$ of fixation at the target, a liquid reward was given. The intertrial interval was $3 \mathrm{~s}$. The sequence of the position of the target was pseudorandom subject to the constraint that within every four trials that contained two trials for each of the two locations, the order was determined randomly. In one block of experiment consisting of 20-28 trials (10-14 trials for each direction), reward was always larger $(0.4 \mathrm{ml})$ for one target direction of the target and smaller $(0.05$ or $0 \mathrm{ml})$ for the other target direction (Fig. $1 A, B$, left-large and right-small). Even for small-reward trials, the animal had to make a correct saccade; if the saccade was incorrect, the same trial was repeated until the saccade was made correctly. In the second block, the direction of reward bias was reversed (Fig. $1 A, B$, right-large and left-small). For completion of one "session," these two kinds of blocks with opposite reward schedules were alternated two or three times so that a total of four to six blocks were performed (Fig. $1 B$ ). Other than given reward, there was no external cue as to which direction was more rewarded or when the block was changed. To examine whether saccadic eye movement changed after drug injection regardless of the reward condition, we used the same visually guided saccade task, but with equal reward for both targets. The amount of reward was typically the same as that in the largereward trials in the biased reward task. One session of the equal-reward saccade task consisted of 20 trials (10 trials for each direction).

Drug injection. After implanting the recording chamber, we obtained magnetic resonance images of the brain. This allowed us to determine the position of the electrode or the injection cannula relative to the recording chamber. To determine injection sites, we first performed single-unit recording using the saccade task with position-biased rewards (Fig. 1A) in a wide area in the caudate to determine the region related to the task. The anteroposterior extent of the recording sites was from $8 \mathrm{~mm}$ anterior to $8 \mathrm{~mm}$ posterior to the anterior commissure, which corresponded to anterior 10-26 mm (monkey S) and 7-23 mm (monkey L) in HorsleyClarke coordinates. Task-related activity in the caudate included visual, presaccadic, and pretarget anticipatory activity (Hikosaka et al., 2000). Neurons were determined task-related if activity of any of the following task periods were significantly modulated (Kruskal-Wallis test, $p<$ $0.01)$ : early, mid, and late fixation period $(0-400,400-800,800-1200$ 
$\mathrm{ms}$ after fixation onset), posttarget period (100 ms after target onset), presaccadic period (100 ms before saccade onset), postsaccadic period (200 ms after saccade onset), and reward period (300 ms after reward onset).

The positions of recordings and injections were determined using a grid system (a plastic cylinder that has a two-dimensional array of holes at every $1 \mathrm{~mm}$ and is fitted to the recording chamber). First, a stainlesssteel guide tube [outer diameter (o.d.), $0.6 \mathrm{~mm}$; inner diameter (i.d.), $0.35 \mathrm{~mm}$ ] was inserted through a grid hole and, after penetrating the dura, it was lowered until its tip reached $2-3 \mathrm{~mm}$ above the upper edge of the caudate. As an injection tube, we used a stainless-steel tube (o.d., 0.2 $\mathrm{mm}$; i.d., $0.1 \mathrm{~mm}$ ), which was connected to the polyethylene tubing (o.d., $3 \mathrm{~mm}$ ), which was in turn connected to the Hamilton syringe. The drug solution was pressure-injected, $0.2 \mu$ l every $30 \mathrm{~s}$ for 10 times, for a total of $2 \mu \mathrm{l}$. We used $((R)-(+)$-7-chloro-8-hydroxy-3-methyl-1-phenyl2,3,4,5-tetrahydro- $1 H$-3-benzazepine) (SCH23390; $8 \mu \mathrm{g} / \mu \mathrm{l})$ as a dopamine $\mathrm{D}_{1}$ antagonist and Eticlopride hydrochloride $(6 \mu \mathrm{g} / \mu \mathrm{l})$ as a dopamine $\mathrm{D}_{2}$ antagonist (Sigma, St. Louis, $\mathrm{MO}$ ), both directly dissolved by saline. These doses were chosen based on the previous reports (Watanabe and Kimura, 1998; Bari and Pierce, 2005). We also injected saline as a separate experiment to ensure the effect was not caused by any mechanical effect by liquid injection (data are in supplemental material, available at www.jneurosci.org).

After inserting an injection tube, the animal performed one session of the biased-reward saccade task (at least four blocks or 80-112 trials) and one session of the equal-reward saccade task (at least 20 trials), and the data were used as preinjection control. Soon after the injection was completed (within $5 \mathrm{~min}$ ), the animal started performing the same biased and equal-reward saccade tasks. One session for each task took 10-15 min to complete. After injection, these two kinds of saccade tasks were repeated for 45-60 min until the effect was no longer observed. We used the data that were obtained within $30 \mathrm{~min}$ after injection as the postinjection data.

Data analysis. We analyzed saccade parameters (reaction time, peak velocity, and amplitude) in correct trials. The reaction time was measured from the target onset to the saccade onset. Because there was no external cue that indicates switch between blocks, the very first trial of the block was likely to carry the behavioral context of the previous block. On the other hand, after extensive training, the monkey might predict the switch of the block around the end of the block. Therefore, we excluded the first and last trials in each block for statistical comparison between conditions. Incorrect trials were classified into no fixation (eye position was not on the fixation point for $1500 \mathrm{~ms}$ after its onset), fixation break (eye position was not maintained within $2^{\circ}$ around the fixation point until target onset), wrong saccade (saccade did not reach the point within $5^{\circ}$ around the target), and slow response (saccade did not start within 500 $\mathrm{ms}$ after target onset), and their frequencies were computed for each session.

Statistical analyses of saccade parameters in correct trials were done at two levels: for within a session (see Fig. $2 A, B$ ) and for the population of sessions (see Figs. $2 C, D, 3$ ). For within-session analyses, we first grouped saccades into four kinds: two directions (contralateral and ipsilateral to the injection side) and two reward conditions (large and small rewards). For each group of saccades, we compared the reaction times in the preinjection session and those in the postinjection sessions using MannWhitney $U$ test. To quantify the separation of the reaction times in largeand small-reward trials for each direction of saccades for each session, we calculated the reaction time bias as follows: the mean reaction time in small-reward trials - the mean reaction time in large-reward trials. To quantify the variability of reaction time, we calculated coefficient of variation (SD/mean) of reaction times for each condition for each session. For population analyses, we compared each of the above variables between the preinjection and postinjection sessions using Wilcoxon signed rank test, separately for the drugs $\left(D_{1}\right.$ and $D_{2}$ antagonists) and saccade directions (contralateral and ipsilateral to the injection site).

In addition to the population analyses for the entire set of experiments for each drug, we analyzed the data obtained from anterior and posterior injection sites separately, because the effects of both drugs were different between the anterior and posterior regions (see Figs. 2C, 5C). To determine the boundary between these regions, we divided the injection sites into the anterior and posterior parts while moving the dividing line in 1 $\mathrm{mm}$ steps from the anterior end until a significant difference was found in the reaction time biases obtained from the anterior and posterior parts $(p<0.05$, Mann-Whitney $U$ test). We then termed the anterior and posterior parts the midcaudate and the postcaudate, respectively. The anterior part was termed the midcaudate because it was still a middle part of the caudate nucleus anatomically. Additional analyses were performed separately for each region to better characterize the effects (see Figs. $2 D$, 3, 5D, 6; for midcaudate, see supplemental Figs. 3, 4).

To study the time course of the effect within a session by drug injections, we first plotted the normalized reaction time against the trial number (see Fig. 4A). Normalization of the reaction times was necessary because both monkeys had idiosyncratically longer reaction times for one direction of saccades, and overall reaction times were different between monkeys. To normalize reaction times for each experiment, we first pooled reaction times for all saccades in both preinjection and postinjection sessions for each direction of saccades and obtained the mean and SD. We then computed $z$-value for a given trial as follows: (given reaction time - mean reaction time)/SD. The data were then averaged across experiments. As shown in the Figures $4 A$ and $7 A$, the value at each bin indicates the grand average of the normalized reaction times in the $n$th trial before and after the transitions. To quantify how quickly saccade reaction times adapted to the change in the reward condition, we first computed the reaction time bias separately for the early period (the first 10 trials except for the first trial) and the late period (the last 10 trials except for the last trial) and made a pair-wise comparison between the values before and after drug injections (see Fig. $4 B$ ). To further examine in which of the large or small-reward condition the adaptation process was affected by the drug injection, we computed the changes in reaction times between the early and late periods in each of the large and small-reward conditions and made a pair-wise comparison between the values before and after drug injections (see Fig. 4C).

\section{Results}

Before injection of dopamine antagonists, monkeys' saccadic reaction times changed reliably and flexibly depending on the position-reward mapping, as reported previously (Lauwereyns et al., 2002b). In a typical example shown in Figure $2 A$, the reaction times were consistently shorter in the large-reward trials (median, $104.5 \mathrm{~ms}$; mean, $106.4 \mathrm{~ms}$; SE, $8.5 \mathrm{~ms}$ ) than in small-reward trials (median, $172 \mathrm{~ms}$; mean, $170.8 \mathrm{~ms}$; SE, $16.0 \mathrm{~ms} ; p<0.0001$, Mann-Whitney $U$ test). When the direction of the reward bias was switched (i.e., block was changed), the reaction times changed within two or three trials. [Because there was no explicit cue to indicate when the reward schedule (i.e., block) would be changed, there was no significant change in reaction time on the very first trial of each block. The seemingly abrupt changes in reaction time across blocks, which are observed in Figures 2, A and $B$, and $5, A$ and $B$, actually occurred on the second or later trials in a block after some trials that induced saccades in the other direction (data not shown) (Watanabe and Hikosaka, 2005).] After the change, the reaction times remained stable during the block. As a measure of the ability of the animal to adjust the reaction times based on expected reward, we computed the reaction time bias, the mean reaction time in small-reward trials minus the mean reaction time in large-reward trials. In the example shown in Figure $2 A$, the reaction time bias was $64 \mathrm{~ms}$.

To test the effect of local blockade of dopamine receptors in the caudate, we injected dopamine $\mathrm{D}_{1}$ antagonist (SCH23390) $(n=21)$, dopamine $\mathrm{D}_{2}$ antagonist (Eticlopride) $(n=23)$, or saline $(n=13)$ unilaterally. Before the drug injection experiments, we performed single-unit recording using the saccade task with position-biased rewards (Fig. $1 A$ ) in a wide area in the caudate. As reported previously, many caudate neurons were related to the saccade task (see Materials and Methods), and their activities were strongly modulated by the reward condition (i.e., large 

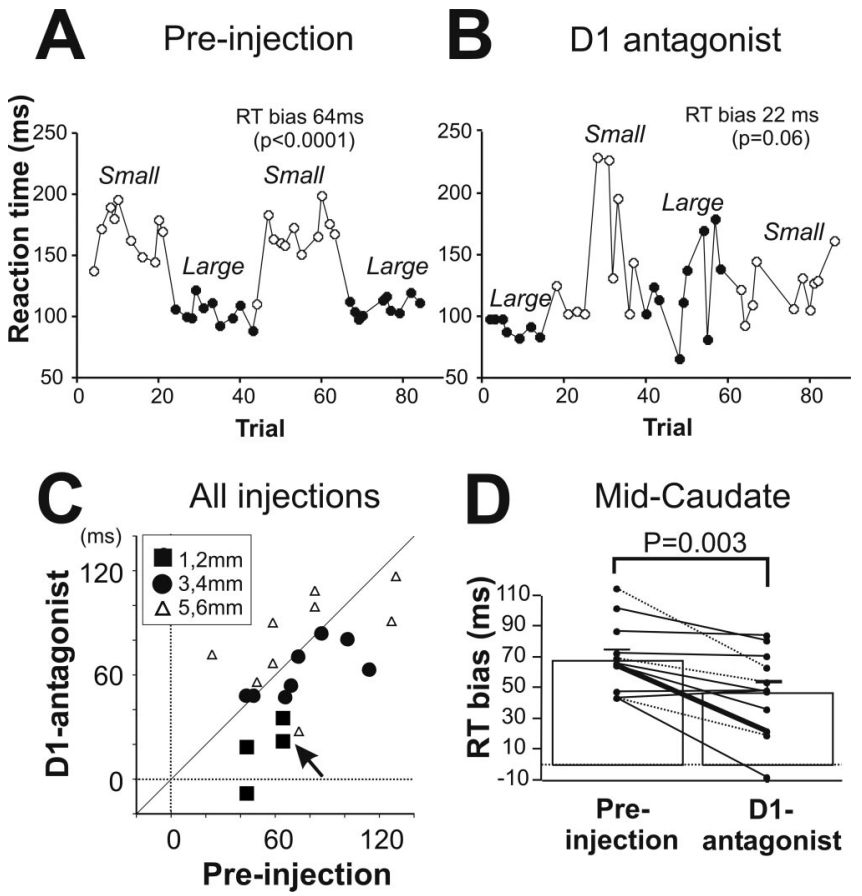

Figure 2. Reward-dependent reaction time bias was attenuated by $D_{1}$ antagonist injection. $\boldsymbol{A}, \boldsymbol{B}$, An example of $\mathrm{D}_{1}$ antagonist injection experiment with data collected before $(\boldsymbol{A})$ and after $(\boldsymbol{B})$ the injection. The injection was made in the right, midcaudate (indicated in Fig. 1C). Reaction times for leftward saccades (contralateral to the injection site) are plotted against the trial number. The leftward saccades were followed by small reward in one block of trials (open circles) and large reward in another block (filled circles). The data points are not regularly spaced because the order of leftward and rightward (data not shown) saccades was pseudorandom. The difference in the mean saccade reaction times between large- and small-reward trials was computed as the reaction time bias (RT bias) and the $p$ value of Mann-Whitney $U$ test (see Materials and Methods). $C$, Reaction time biases before and after individual $D_{1}$ antagonist injections ( $n=21$ ) for contralateral saccades are plotted in abscissa and ordinate, respectively. Different symbols indicate the distance of injection sites from the anterior commissure: $1-2 \mathrm{~mm}$ (filled squares), 3-4 mm (filled circles), 5-6 mm (open triangles). The anterior injection sites $(1-4 \mathrm{~mm})$ and the posterior sites $(5-6 \mathrm{~mm})$ were designated as the midcaudate and the postcaudate, respectively (see Results). $\boldsymbol{D}$, Changes in the reaction time bias from preinjection control to $D_{1}$ antagonist injection to midcaudate $(n=12)$. The lines show the data of individual experiments; solid and dotted lines indicate the data from monkey $S$ and monkey $L$, respectively. Statistical difference in data between control and test is shown by the $p$ value of Wilcoxon signed rank test. Error bars indicate $1 \mathrm{SE}$. The arrow in $\boldsymbol{C}$ and the thick line in $\boldsymbol{D}$ indicate the data presented in $\boldsymbol{A}$ and $\boldsymbol{B}$.

or small reward) (Kawagoe et al., 1998; Watanabe et al., 2003) or by the rewarded position (Lauwereyns et al., 2002b; Takikawa et al., 2002a). Because task-related neurons were found mainly in the caudate posterior to the anterior commissure, in agreement with a previous report (Hikosaka et al., 1989), we performed injections mainly in the part of caudate posterior to the anterior commissure.

We found that the adaptive modulation of saccades by reward was affected differently depending on the kinds of dopamine antagonists. In the following text, we will concentrate on the changes in the saccadic reaction time because it showed consistent and significant changes across experiments (see supplemental Tables 1-6, available at www.jneurosci.org as supplemental material, for other saccadic parameters). Incorrect trials were rare (typically $<5 \%$ ), and the frequency of any type of errors (no fixation, fixation break, wrong saccade, and slow response) showed no significant changes by any of the drug injections. These incorrect trials were thus excluded from further analyses.

\section{Effects of dopamine $D_{1}$ antagonist injection}

The reward effect on the reaction time that had been seen during preinjection control (Fig. $2 \mathrm{~A}$ ) became smaller after injection of the $\mathrm{D}_{1}$ antagonist $\mathrm{SCH} 23390$ (Fig. $2 \mathrm{~B}$ ). In this example, the $\mathrm{D}_{1}$ antagonist was injected in the right caudate, $2 \mathrm{~mm}$ posterior to the anterior commissure (Fig. 1C, arrow). The saccade performance was recorded starting $\sim 3$ min after the injection was completed. The reaction times of leftward saccades (contralateral to the injection site) were no longer reliably modulated by the reward condition (median, $102.0 \mathrm{~ms}$; mean, $111.0 \mathrm{~ms}$; SE, $32.0 \mathrm{~ms}$ in the large-reward trials and median, $125.0 \mathrm{~ms}$; mean, $133.1 \mathrm{~ms}$; SE, $43.1 \mathrm{~ms}$ in small-reward trials; $p=0.06$, Mann-Whitney $U$ test). The reaction time bias $(22 \mathrm{~ms})$ was smaller than the value in the preinjection control (Fig. $2 A$ ).

We made 21 ( 17 in monkey $\mathrm{S}$, four in monkey $\mathrm{L}$ ) injections of the $\mathrm{D}_{1}$ antagonist and obtained similar results. In Figure $2 \mathrm{C}$ are shown, for individual experiments, the reaction time biases before (abscissa) and after (ordinate) the drug injections. Similar to the example shown in Figure $2 \mathrm{~A}$, the reaction time bias decreased after the injections in many experiments (data points below the equity line), but a statistical analysis did not indicate a significant change (Wilcoxon signed rank test, $p=0.08$ ). We found, however, that the drug effect was stronger in more anterior injections. Correlation between the distance from the anterior commissure and the degree of attenuation in the reaction time bias was significant (Spearman rank correlation, $p=0.004 ; \rho=0.65 ; n=21$ ). To determine the regional boundary, we divided the injection sites into the anterior and posterior parts while moving the dividing line from the anterior end. A significant difference in the reaction time bias between anterior and posterior injections was found between 4 and $5 \mathrm{~mm}$ from the anterior commissure $(p<$ 0.03, Mann-Whitney $U$ test; see Materials and Methods). We therefore designated the area $1-4 \mathrm{~mm}$ from the anterior commissure as midcaudate and the area $5-6 \mathrm{~mm}$ from the anterior commissure as postcaudate. The reaction time bias became significantly smaller after $D_{1}$ antagonist injections in the midcaudate (total, 12 injections; nine in monkey S; three in monkey $\mathrm{L} ; p=$ 0.003 ) (Fig. $2 C$, filled symbols, $D$ ) but not in the postcaudate (total, nine injections; seven in monkey $\mathrm{S}$; two in monkey $\mathrm{L} ; p=$ 0.77 ) (Fig. 2C, open symbols). In the following, we focus on the effects of $D_{1}$ antagonist in the midcaudate.

The attenuation of the reaction time bias was mainly caused by increases in reaction time on large-reward trials (Fig. $3 A, B$ ). In Figure $3 A$, we compare the distributions of reaction times on all trials in the gap-absent condition (no time gap between the fixation offset and target onset) before (top) and after (bottom) $\mathrm{D}_{1}$ antagonist injections in the midcaudate. The reaction times became significantly longer on large-reward trials $(p=0.0001)$ (Fig. 3A, left) but showed no significant change on small-reward trials $(p=0.06)$ (Fig. $3 A$, right). In the gap-present condition, the reaction times increased on large-reward trials $(p=0.0001$; $n=66$ for preinjection control; $n=61$ for injections) and decreased on small-reward trials ( $p=0.0005$ for small-reward trials; $n=64$ for preinjection control; $n=71$ for injections). Figure $3 B$ shows the results of the analysis of single experiments (i.e., comparison between preinjection and postinjection sessions). The reaction times became significantly longer in 6 of 12 experiments on the large-reward trials (Fig. $3 B$, left, filled circles); in contrast, the reaction times became shorter in only one experiment under small-reward conditions (Fig. 3B, right, filled circles). A pair-wise population comparison for individual experiments indicates that the mean reaction times on large-reward trials were significantly prolonged ( $p=0.004$, pair-wise compar- 

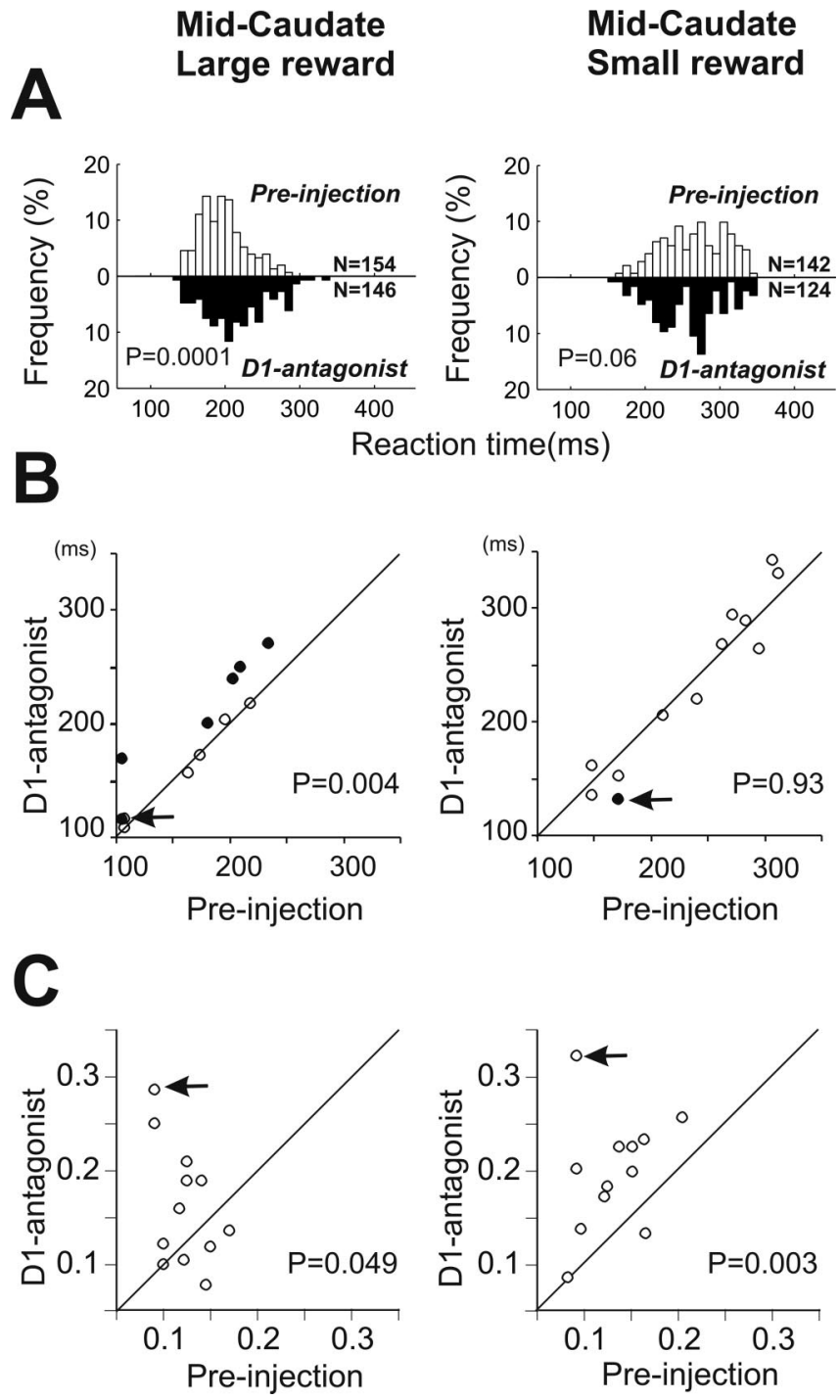

Figure 3. Changes in saccade reaction times by $D_{1}$ antagonist injection in the midcaudate on large-reward trials (left column) and on small-reward trials (right column). $\boldsymbol{A}$, The distributions of reaction times on all trials obtained from eight experiments without a gap between fixation offset and target onset. In each panel, the top (white bars) and bottom (black bars) histograms indicate the preinjection and postinjection sessions, respectively. $\boldsymbol{B}$, Mean reaction times for individual experiments. Filled circles indicate significant differences between the preinjection and postinjection sessions (Mann-Whitney $U$ test, $p<0.05$ ); open circles indicate nonsignificant differences. $\boldsymbol{C}$, Coefficient of variation of reaction times. The arrows in $\boldsymbol{B}$ and $\boldsymbol{C}$ indicate the data presented in Figure $2, A$ and $B$.

ison for individual experiments), whereas the mean reaction times on small-reward trials did not change significantly ( $p=$ $0.93)$; similar results were obtained for the median reaction times ( $p=0.016$ for large reward; $p=0.13$ for small-reward trials) (supplementary Fig. 7A, available at www.jneurosci.org as supplemental material). We also found that the variability of reaction times increased, as shown by an increase in coefficient of variation (Fig. 3C). Similar effects were observed for saccades ipsilateral to the injection site (supplementary Fig. 1, available at www. jneurosci.org as supplemental material).

Injection of $\mathrm{D}_{1}$ antagonist into the midcaudate also affected the time course of the reward effect on the reaction time within a block. Figure $4 A$ shows the changes in the normalized reaction time (see Materials and Methods) averaged across all sessions, aligned at the times when the reward condition was switched
A

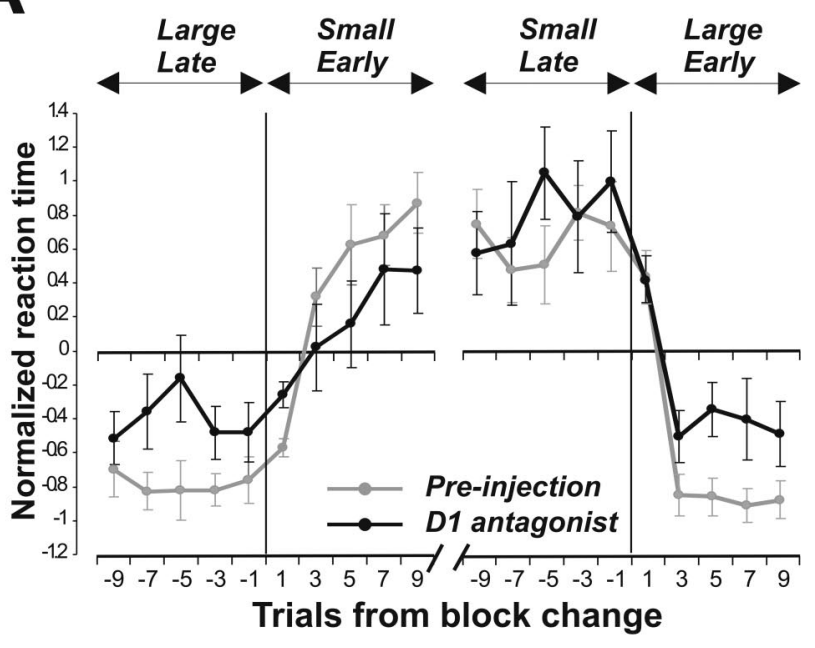

B
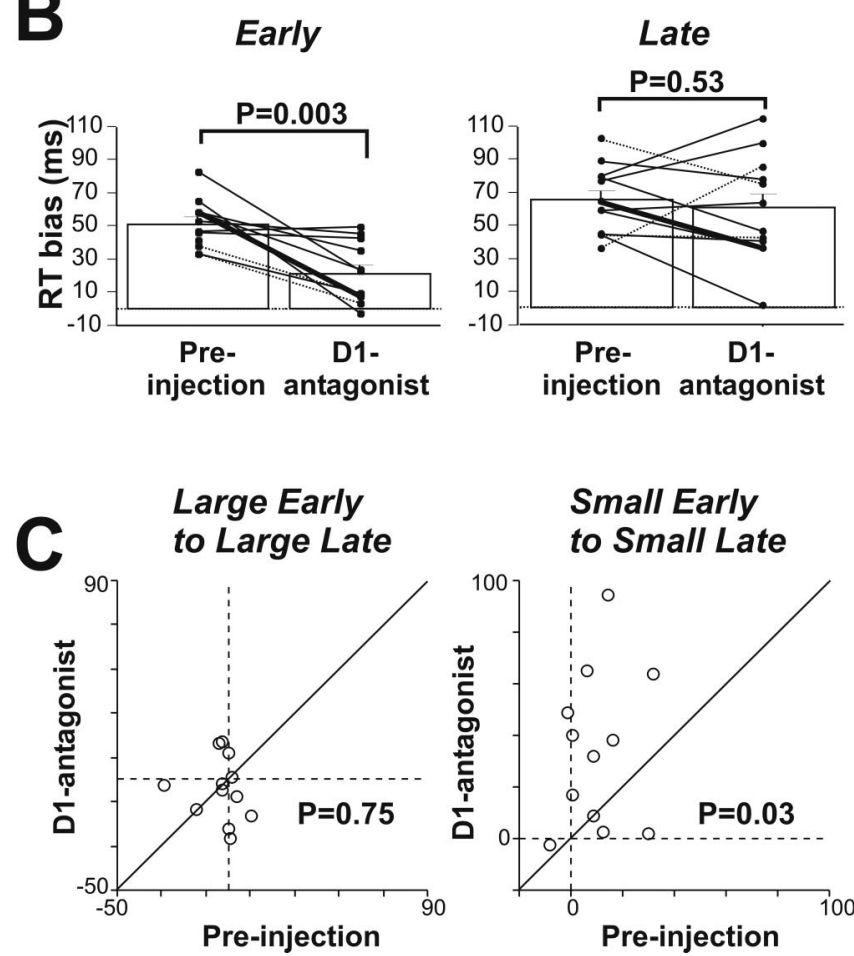

Small Early

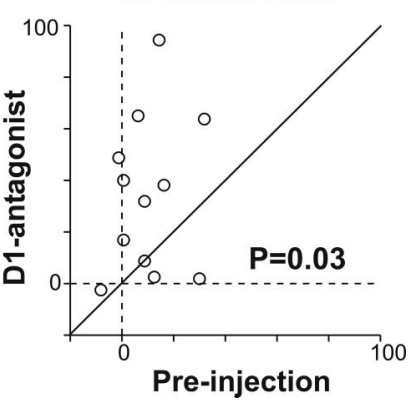

Figure 4. The effects of $D_{1}$ antagonist were stronger during the earlier period of block after the reversal of position-reward contingency. $\boldsymbol{A}$, Trial-by-trial changes in reaction times for contralateral saccades. The preinjection data are shown in gray; the postinjection data are in black. Normalized reaction times (see Materials and Methods) averaged across all 12 experiments with injections in the midcaudate are plotted against the number of trials before and after the time when the block (position-reward contingency) was changed. Data for adjacent two trials are averaged: trial number 1 indicates the average of the data for trial 1 and 2; trial number 3 indicates the average for trial 3 and 4 . $\boldsymbol{B}$, The change in the reaction time (RT) bias for contralateral saccades during the early (left) and late (right) periods of block. The format is the same as in Figure 2D.C, Changes in the mean reaction times from the early to late period of the block, shown separately for the large-reward block (left) and the small-reward block (right). The data were obtained for contralateral saccades before (abscissa) and after (ordinate) $D_{1}$ antagonist injections in the midcaudate $(n=12)$. Error bars indicate $1 \mathrm{SE}$.

from the large to small reward and from the small to large reward. During the preinjection control, the reaction time changed quickly in both types of switch (as exemplified in Fig. $2 A$ ). This pattern changed after the $D_{1}$ antagonist injection; the reaction 
A Pre-injection B D2 antagonist
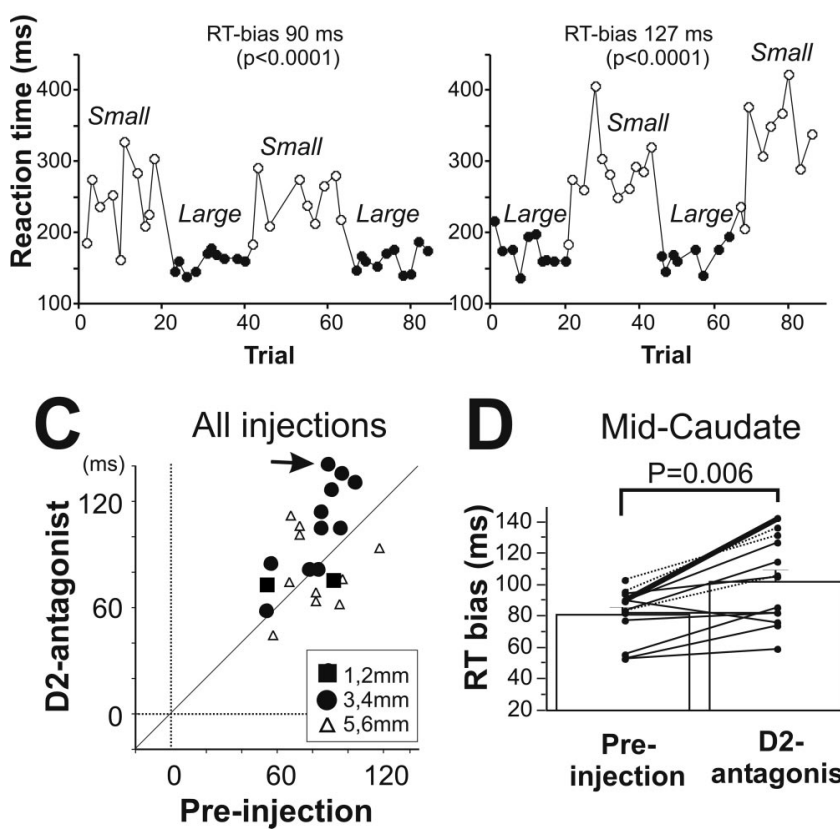

D Mid-Caudate

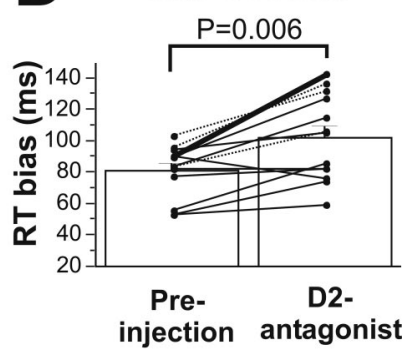

Figure 5. Reward-dependent reaction time (RT) bias was enhanced by $D_{2}$ antagonist injection. The same format as Figure 2.

time appeared to change more slowly after the reward condition was switched. To quantify this effect, we divided each block of trials into the early period (the first 10 trials, except for the first trial) and the late period (the last 10 trials, except for the last trial) and examined, for each period, the changes in the reaction time bias by the $D_{1}$ antagonist. As shown in Figure $4 B$, these values were attenuated in the early period, rather than in the late period. In other words, although the monkey was still able to differentiate between the large and small-reward conditions, the adaptation to the new reward condition was slowed by the $\mathrm{D}_{1}$ antagonist. To examine whether the adaptation was slowed in the large or smallreward condition, or both, we analyzed the changes in the reaction times from the early period to the late period in each of the large and small-reward conditions, as shown in Figure 4C. The changes became significantly larger after $D_{1}$ antagonist injections in the small-reward condition (small/early to small/late) ( $p=$ 0.03 ) but not in the large-reward condition (large/early to large/ late) $(p=0.75)$. The results indicate that the adaptation was slowed under the small-reward condition.

\section{Effects of dopamine $\mathrm{D}_{2}$ antagonist injection}

Injection of a $\mathrm{D}_{2}$ antagonist, Eticlopride, also affected saccades, but in a different manner. Figure $5, A$ and $B$, exemplifies the changes in the reaction time of rightward saccades before (Fig. $5 A$ ) and after (Fig. $5 B$ ) the injection of the $\mathrm{D}_{2}$ antagonist in the left midcaudate, $4 \mathrm{~mm}$ posterior to the anterior commissure (Fig. 1C). The reaction time bias increased from 90 to $127 \mathrm{~ms}$.

We made 23 (18 in monkey S, five in monkey L) injections of the $\mathrm{D}_{2}$ antagonist, and the reaction time biases before and after the injections are shown for individual experiments (Fig. 5C). Similar to the example shown in Figure $5 A$, the reaction time bias increased after the injections in many experiments (data points above the equity line), but a statistical analysis did not indicate a significant change (Wilcoxon signed rank test, $p=0.06$ ). Unlike $\mathrm{D}_{1}$ antagonist injections, the relationship between the distance

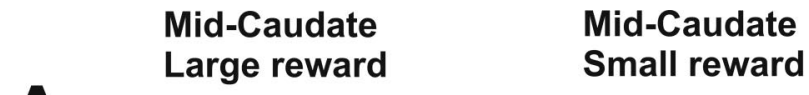

A Small reward

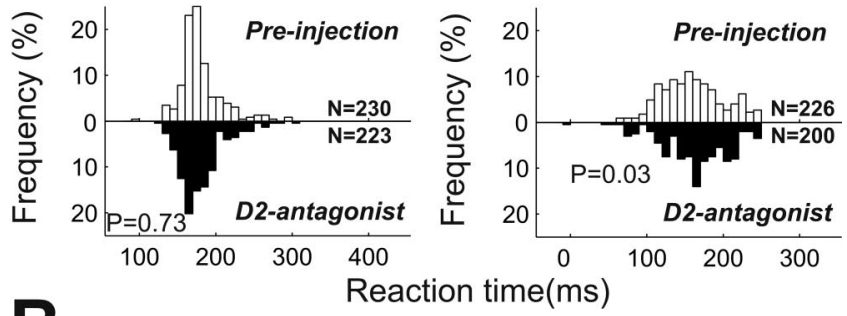

B
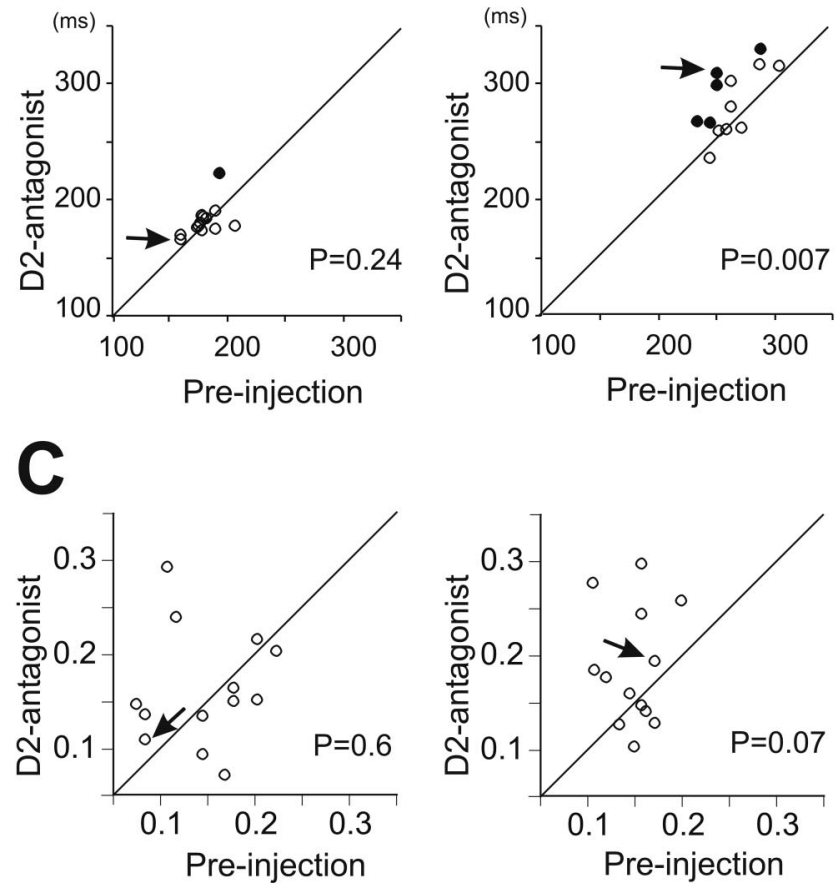

Figure 6. Changes in saccade reaction times by $\mathrm{D}_{2}$ antagonist injection in the midcaudate for large-reward trials (left column) and small-reward trials (right column). The same format as Figure 3.

from the anterior commissure and the change in the reaction time bias was not monotonic (Spearman rank correlation, $p=$ $0.1 ; \rho=0.34 ; n=23$ ). Nonetheless, similar to the $\mathrm{D}_{1}$ antagonist injections, we found a regional difference between anterior and posterior injections at the level between 4 and $5 \mathrm{~mm}$ from the anterior commissure ( $p<0.05$, Mann-Whitney $U$ test). The reaction time bias became significantly larger after $D_{2}$ antagonist injections in the midcaudate (total, 13 injections; 10 in monkey S; three in monkey L; $p=0.006$ ) (Fig. $5 C$, filled symbols, $D$ ) but not in the postcaudate (total, 10 injections; eight in monkey $S$; two in monkey L; $p=0.88$ ) (Fig. $5 C$, open symbols). In the following, we focus on the effects of $\mathrm{D}_{2}$ antagonist in the midcaudate.

The enhancement of the reaction time bias was mainly caused by increases in reaction times on small-reward trials (Fig. 6A, B). As shown in Figure $6 A$, the reaction times became significantly longer on small-reward trials $(p=0.03)$ (Fig. $6 A$, right) but showed no significant change on large-reward trials $(p=0.73)$ (Fig. 6A, left). The results based on individual experiments (Fig. $6 B$ ) indicate that the reaction times became significantly longer in 5 of 13 experiments on the small-reward trials (Fig. $6 \mathrm{~B}$, right, filled circles); in contrast, the reaction time became longer in only 
one experiment on the large-reward trials (Fig. 6B, left, filled circles). A pair-wise population comparison for individual experiments indicates that the mean reaction times on small-reward trials were significantly prolonged $(p=0.007)$, whereas the mean reaction times on large-reward trials did not change significantly ( $p=0.24$ ); similar results were obtained for the median reaction times (supplementary Fig. $7 B$, available at www.jneurosci. org as supplemental material). The variability of reaction times was not significantly changed (Fig. $6 C$ ). Unlike the $\mathrm{D}_{1}$ antagonist, the significant effects of the $\mathrm{D}_{2}$ antagonist were observed for contralateral saccades but not for ipsilateral saccades (supplementary Fig. 2, available at www.jneurosci.org as supplemental material).

The $\mathrm{D}_{2}$ antagonist changed the time course of the reward effect on the reaction times differently from the $\mathrm{D}_{1}$ antagonist. As shown in Figure $7 A$, after the switches of the reward condition, the reaction time changed as quickly as the preinjection control. The prolongation of reaction times on small-reward trials became clear in the late block period. As a result, the increase in the reaction time bias was statistically significant in the late period but not in the early period (Fig. $7 B$ ). Unlike $D_{1}$ antagonist, $D_{2}$ antagonist injections did not affect the speed of adaptation of the reaction times significantly, as shown in Figure $7 C(p=0.15$, small/early to small/late; $p=0.70$, large/early to large/late).

In sum, the $\mathrm{D}_{2}$ antagonist caused gradual prolongation of reaction times of contralateral saccades on small-reward trials, which led to an enhancement of the reaction time bias.

\section{Effect of dopamine $D_{1}$ and $D_{2}$ antagonist into posterior caudate}

We found the effects of both the $\mathrm{D}_{1}$ and $\mathrm{D}_{2}$ antagonists were weaker when they were injected in the posterior part of the caudate, which was $>5 \mathrm{~mm}$ posterior to the anterior commissure (Fig. 1C). We made nine injections of the $\mathrm{D}_{1}$ antagonist in the posterior caudate (seven in monkey S, two in monkey L). As a population, there were no significant changes in the reaction time bias (supplementary Fig. $3 A$, D, available at www.jneurosci.org as supplemental material). The only significant effects were an increase in reaction times on large-reward trials (supplementary Fig. 3B, available at www.jneurosci.org as supplemental material) and an increase in the variability of reaction times on smallreward trials (supplementary Fig. $3 C$, available at www.jneurosci. org as supplemental material), both for contralateral saccades.

We also made 10 injections of the $\mathrm{D}_{2}$ antagonist in the postcaudate (eight in monkey S, two in monkey L). The reaction time bias showed no change (supplementary Fig. $4 A, D$, available at www.jneurosci.org as supplemental material). The significant increases in reaction times on large-reward trials for both contralateral and ipsilateral saccades (supplementary Fig. $4 B, E$, available at www.jneurosci.org as supplemental material) had no major impact on the reaction time bias.

Control experiments: equal-reward task and saline injections Previous studies have shown that caudate activity is more prevalent in the biased-reward task than in an equal-reward task during which an equal amount of reward is given for both directions (Takikawa et al., 2002a). This suggests that the effect of dopamine blockade on behavior should be dependent on reward context. To determine whether the effects observed above are specific to the biased-reward task, we examined behavior during performance of the equal-reward saccade task.

Significant changes in the reaction times were observed only after $\mathrm{D}_{1}$ antagonist injections in the midcaudate, for contralateral saccades (mean, 206.4 to $216.4 \mathrm{~ms} ; p=0.02$ ). Changes in ipsilat-
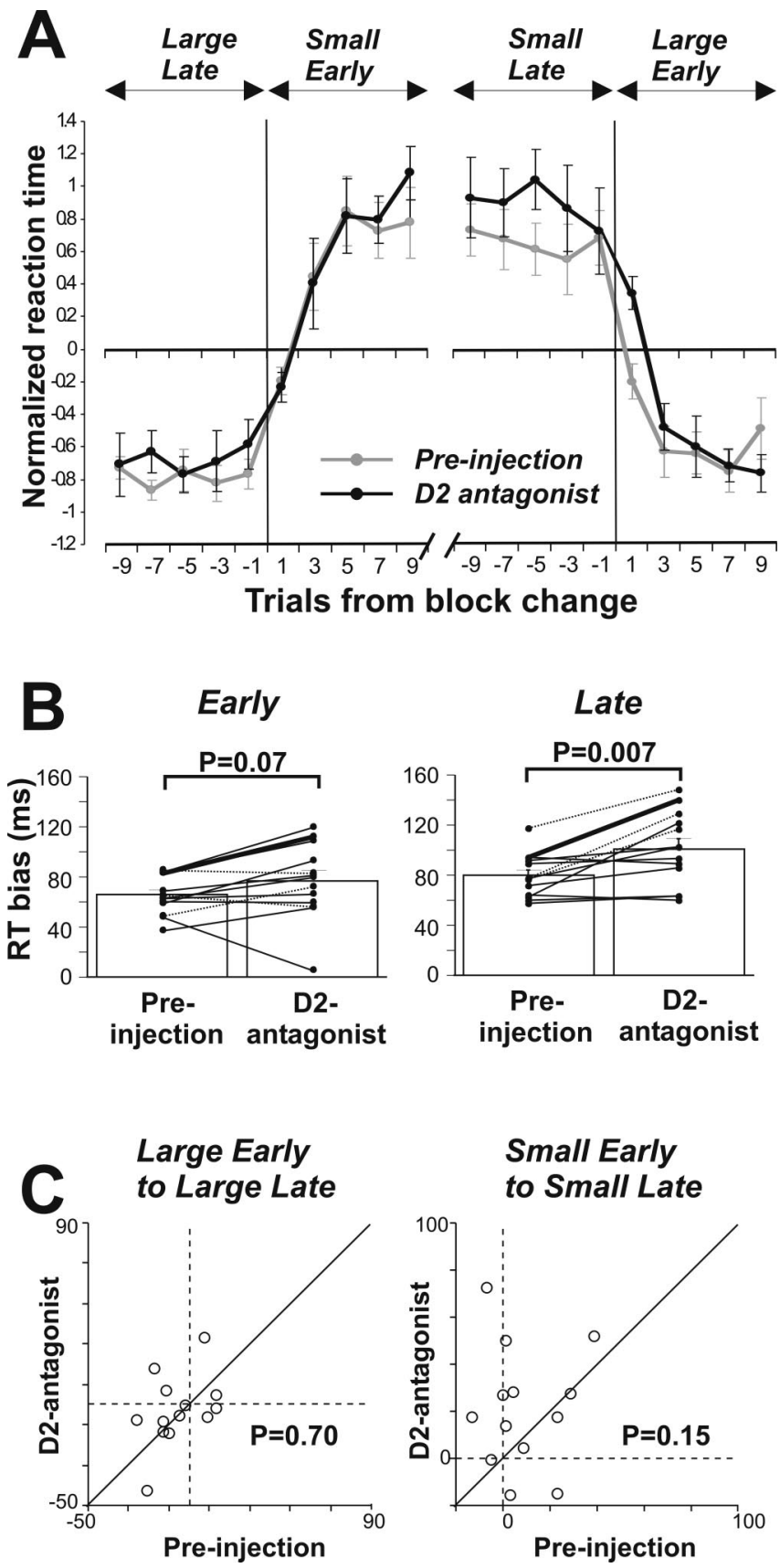

Figure 7. The effects of $D_{2}$ antagonist were stronger some trials after the reversal of positionreward contingency. The same format as Figure 4. RT, Reaction time. Error bars indicate 1SE.

eral saccades did not reach the significant level (240.4 to $250.7 \mathrm{~ms}$; $p=0.13)$. The effects of $\mathrm{D}_{2}$ antagonist injections in the midcaudate showed no significant change (223.5 to $229.1 \mathrm{~ms}, p=0.09$ for contralateral saccades; 204.8 to $197.7 \mathrm{~ms}, p=0.05$ for ipsilateral saccades). Injections of either drug to the postcaudate showed no significant changes. Increases in coefficient of variation for both direction of saccades were observed only for $\mathrm{D}_{2}$ antagonist injections in the midcaudate (contralateral, $p=0.04$; ipsilateral, $p=0.02$ ).

To exclude the possible volume effects by drug injections, we also performed saline injections as separate experiments $(n=9$ for midcaudate; $n=4$ for postcaudate) (supplementary Figs. 5 and 6, available at www.jneurosci.org as supplemental material). There were no consistent changes. 


\begin{tabular}{|c|c|c|c|c|}
\hline \multirow{2}{*}{$\frac{\text { Drug }}{\text { Saccade }}$} & \multicolumn{2}{|c|}{ D1 antagonist } & \multicolumn{2}{|c|}{ D2 antagonist } \\
\hline & Contra & Ipsi & Contra & Ipsi \\
\hline \multicolumn{5}{|l|}{$\begin{array}{l}\text { Reaction times in } \\
\text { Biased-reward task }\end{array}$} \\
\hline $\begin{array}{l}\text { Large-Small reward } \\
\text { difference (bias) }\end{array}$ & & & & NS \\
\hline Large reward & & & NS & NS \\
\hline Small reward & NS & NS & & NS \\
\hline $\begin{array}{l}\text { Switch across } \\
\text { blocks }\end{array}$ & & NS & NS & NS \\
\hline Variance & & & NS & NS \\
\hline $\begin{array}{l}\text { Reaction times in } \\
\text { Equal-reward task }\end{array}$ & & NS & NS & NS \\
\hline
\end{tabular}

Figure 8. Summary of the effects of dopamine $D_{1}$ and $D_{2}$ antagonist injections to the midcaudate. The direction of arrows indicates an increase (upward) or a decrease (downward) of the values. NS, Statistically not significant; Contra, contralateral; Ipsi, ipsilateral.

\section{Discussion}

Our findings that local blockade of dopamine receptors in the caudate induced changes in reward-dependent reaction time provide two important conclusions. First, the caudate is a source of reward-dependent modulation of a particular motor behavior, namely saccadic eye movement. Second, dopamine $D_{1}$ and $D_{2}$ receptors are involved in the reward-dependent modulation of saccades, but in different manners.

The effects of dopamine antagonist injections on the performance of the biased-reward saccade task, summarized in Figure 8 , cannot be explained simply by a general change in motor preparation, arousal, or motivational level. First, the frequency of fixation break, a measure of general motivation (Roesch and Olson, 2004), was not changed significantly. Second, more importantly, the effects were task dependent. In the $\mathrm{D}_{1}$ antagonist injections, the prolongation of reaction times on large-reward trials in the biased-reward task is consistent with the effect observed in the equal-reward task, but the reaction times on small-reward trials were not increased. Although the effect was bilateral in the biased-reward task, the effect on the equal-reward task was significant only for contralateral saccades. Increases in reaction time variability was evident in the biased-reward task, but not in the equal-reward task. $\mathrm{D}_{2}$ antagonist injections did not cause significant prolongation of the reaction times in the equal-reward task, but they did so for contralateral saccades on the small-reward trials in the biased-reward task. These task-dependent effects of dopamine antagonists are consistent with the task-dependent activity of caudate neurons that is sensitive to the difference in expected reward value between targets (Takikawa et al., 2002a; Cromwell et al., 2005).

\section{Dopamine $\mathrm{D}_{1}$-mediated effects on reward-modulation of saccades}

The effects of $\mathrm{D}_{1}$ antagonist injection in the biased-reward task were characterized by attenuation of the reward-dependent reaction time bias, loss of the stability of reaction times, and slower adaptation to the reversal of position-reward contingency. The attenuation of the reaction time bias was caused by the prolongation of reaction times on large-reward trials and unchanged reaction times on small-reward trials. At the neural network level, such reward-condition-specific effects of $\mathrm{D}_{1}$ antagonist may be explained by the following observations. First, in the biasedreward saccade task, dopamine neurons fire phasically when the saccade target indicates a large reward (Kawagoe et al., 2004), which should cause a phasic increase in the dopamine level in the caudate (Cragg et al., 2002). Second, in the striatum, $D_{1}$ receptors are preferentially expressed by neurons that belong to the direct pathway (i.e., projecting to the substantia nigra directly) (Gerfen et al., 1990; Surmeier et al., 1996). Third, in the anesthetized animals, dopamine increases the excitability of caudate neurons, and this effect was reduced by $\mathrm{D}_{1}$ antagonist (Gonon, 1997; West and Grace, 2002). These observations suggest that $D_{1}$ antagonist injection into the caudate would attenuate the responses of nigraprojecting caudate neurons to a large-reward indicating target, which leads to a weaker disinhibition of neurons in the superior colliculus (Hikosaka et al., 2000) and consequently the prolongation of saccade reaction times on large-reward trials.

The above interpretation assumes that dopamine neurons act quickly on caudate neurons to change saccade reaction time on a single trial. However, this may not be realistic, considering the metabotropic nature of dopamine actions. An alternative mechanism may be dopamine-dependent plasticity in cortico-striatal synapses (Calabresi et al., 1996; Reynolds and Wickens, 2002; Lovinger et al., 2003; Mahon et al., 2004). A conjunction of presynaptic activity in cortico-striatal inputs and postsynaptic activity in caudate neurons leads to long-term potentiation only if a large phasic increase in $D_{1}$ receptor activation occurs simultaneously (Reynolds and Wickens, 2002). In our paradigm, if a particular target is repeatedly associated with a large reward, which would cause dopamine neuron activation (Kawagoe et al., 2004), the cortico-striatal synapses carrying the target signal should undergo long-term potentiation, and therefore caudate neurons respond to the target progressively more strongly, leading to shorter saccade reaction times. $D_{1}$ antagonist should suppress such changes, as we observed as the longer saccade reaction times on large-reward trials. The result is also consistent with previous studies showing that $\mathrm{D}_{1}$ receptor blockade or knock-out disrupts the acquisition of the conditioned approach paradigms (Eyny and Horvitz, 2003; Tran et al., 2005).

We also found that $\mathrm{D}_{1}$ blockade impeded the adaptation of saccade reaction times to the reversal of position-reward contingency. This can be interpreted as slower changes in the efficacy of the cortico-striatal synapses. This phenomenon may be related to the deficits in switching or set-shifting reported in parkinsonian patients (Hayes et al., 1998; Gauntlett-Gilbert et al., 1999; Cools et al., 2001) and in animals with striatal dopamine depletions (Oades, 1985; van den Bos and Cools, 2003; Goto and Grace, 2005).

Another interesting effect of the $D_{1}$ blockade was the increase in the variability of reaction times. The effect is consistent with the finding that shows manipulation of the dopamine system alters the variability and sequential pattern of generic behavior in rodents (Paulus et al., 1993).

\section{Dopamine $\mathrm{D}_{2}$-mediated effects on reward-modulation of saccades}

The effects of the $\mathrm{D}_{2}$ blockade were different from the effects of the $\mathrm{D}_{1}$ blockade. The reaction time bias was even enhanced as a result of the prolongation of reaction times on small-reward trials. $D_{2}$ receptors are preferentially expressed by caudate neurons that belong to the indirect pathway (Gerfen et al., 1990; Surmeier et al., 1996), the action of which would lead to an enhanced inhibition of the superior colliculus (Hikosaka et al., 2000). Because the $\mathrm{D}_{2}$-mediated effect on caudate neurons is inhibitory 
(West and Grace, 2002), dopamine would exert facilitatory effects on superior colliculus neurons via the indirect pathway, similar to its effect on the direct pathway. The apparent discrepancy may be resolved by a common effect of $\mathrm{D}_{1}$ and $\mathrm{D}_{2}$ antagonists: prolongation of saccade reaction times. The prolongation of saccade reaction times occurred on large-reward trials for $\mathrm{D}_{1}$ blockade and on small-reward trials for $\mathrm{D}_{2}$ blockade. It is possible that the $\mathrm{D}_{2}$-mediated inhibitory effect on caudate neurons is necessary to keep minimum facilitatory effects on the superior colliculus for saccades to be generated even on small-reward trials. $\mathrm{D}_{2}$-receptor blockade would reduce the facilitatory effects on saccades on small-reward trials when the dopamine level decreases, leading to prolonged reaction times on small-reward trials.

Note that the schemes described above may be oversimplified, given the recent evidence indicating colocalization of $\mathrm{D}_{1}$ and $\mathrm{D}_{2}$ receptors in single striatal projection neurons (Surmeier et al., 1996; Aizman et al., 2000). It is also possible that $\mathrm{D}_{2}$ antagonist increased activation of the $\mathrm{D}_{1}$-mediated effect through blockade of $\mathrm{D}_{2}$-mediated autoreceptor inhibition of dopamine release (Carter and Muller, 1991). Additional studies should address the coordinated $\mathrm{D}_{1}$ and $\mathrm{D}_{2}$ functions in the control of voluntary behavior.

The laterality of the $\mathrm{D}_{1}$ - and $\mathrm{D}_{2}$-mediated effects is difficult to interpret: $\mathrm{D}_{1}$ blockade effects were bilateral, whereas $\mathrm{D}_{2}$ blockade effects were contralateral. Contralateral effects are easy to understand because most of the connections from the caudate to the superior colliculus through the substantia nigra pars reticulata are ipsilateral (Tulloch et al., 1978) and the superior colliculus controls saccades to the contralateral hemifield (Robinson, 1972). A known exception is a crossed connection from the substantia nigra pars reticulata to the superior colliculus (Beckstead et al., 1981; Jiang et al., 2003). However, there is no evidence, to our knowledge, that the crossed connection preferentially carries the information of the $D_{1}$ receptor (i.e., direct) pathway. On the input side, there is a hint for the difference in laterality: caudate neurons in the direct and indirect pathways tend to receive bilateral and ipsilateral cortical projection, respectively (Lei et al., 2004). It is possible that the outputs of these caudate neurons are organized in the same manner.

\section{Role of dopamine in reward-related learning and motor control}

Behavioral-pharmacological studies have shown an essential role of dopamine in reward- or drug-seeking behavior and related neuronal activity, providing detailed mechanisms dependent on brain location and receptor type (Ikemoto and Panksepp, 1999; van den Bos and Cools, 2003; Wise, 2004; Yun et al., 2004; Goto and Grace, 2005; Tran et al., 2005). Contrasting effects of $D_{1}$ - and $\mathrm{D}_{2}$-mediated effects on reward-related learning and learned behaviors have also been reported (Beninger and Miller, 1998; Eyny and Horvitz, 2003). A majority of these studies have been done either with systemic injection of drugs, or in relation to the function of the ventral striatum. Recently, however, the dorsal striatum has become another focus of research on reward- or drugseeking behavior, which is also heavily dependent on dopamine. Consistent with our findings, it is now considered that dopaminergic input to dorsal striatum provides a reinforcing signal that effectively stamps in stimulus-response associations (Packard and Knowlton, 2002; Wise, 2004). Dopamine level in the dorsal striatum markedly increased in response to a drug-associated cue (Ito et al., 2002) and a dopamine antagonist attenuates such cue controlled reward or drug seeking behavior (Vanderschuren et al., 2005).

Despite the rich literature partially listed above, the precise circuits and functions affected by dopamine receptor activation that alter the behavioral outcome remain unclear. Many studies have indicated that patients of Parkinson's disease and other dopamine deficiencies show impairments in saccade initiation (for review, see Hikosaka et al., 2000). That dopamine release in the caudate is essential for the control of saccades has been shown by unilateral infusion of MPTP (1-methyl-4-phenyl-1,2,3,6-tetrahydropyridine) in the monkey caudate (Kato et al., 1995; Kori et al., 1995; Miyashita et al., 1995).

These experiments, however, did not indicate how dopamine is used to control saccadic eye movements. The results presented in this article provide evidence that dopaminergic modulation of caudate neuronal activity contributes, at least partly, to changes in saccadic eye movement by expected reward.

\section{References}

Aizman O, Brismar H, Uhlen P, Zettergren E, Levey AI, Forssberg H, Greengard P, Aperia A (2000) Anatomical and physiological evidence for D1 and D2 dopamine receptor colocalization in neostriatal neurons. Nat Neurosci 3:226-230.

Amador N, Schlag-Rey M, Schlag J (2000) Reward-predicting and rewarddetecting neuronal activity in the primate supplementary eye field. J Neurophysiol 84:2166-2170.

Bari AA, Pierce RC (2005) D1-like and D2 dopamine receptor antagonists administered into the shell subregion of the rat nucleus accumbens decrease cocaine, but not food, reinforcement. Neuroscience 135:959-968.

Beckstead RM, Edwards SB, Frankfurter A (1981) A comparison of the intranigral distribution of nigrotectal neurons labeled with horseradish peroxidase in the monkey, cat, and rat. J Neurosci 1:121-125.

Beninger RJ, Miller R (1998) Dopamine D1-like receptors and rewardrelated incentive learning. Neurosci Biobehav Rev 22:335-345.

Calabresi P, Mercuri N, Stanzione P, Stefani A, Bernardi G (1987) Intracellular studies on the dopamine-induced firing inhibition of neostriatal neurons in vitro: evidence for D1 receptor involvement. Neuroscience 20:757-771.

Calabresi P, Pisani A, Mercuri NB, Bernardi G (1996) The corticostriatal projection: from synaptic plasticity to dysfunctions of the basal ganglia. Trends Neurosci 19:19-24

Carter AJ, Muller RE (1991) Pramipexole, a dopamine D2 autoreceptor agonist, decreases the extracellular concentration of dopamine in vivo. Eur J Pharmacol 200:65-72.

Cools R, Barker RA, Sahakian BJ, Robbins TW (2001) Mechanisms of cognitive set flexibility in Parkinson's disease. Brain 124:2503-2512.

Cragg SJ, Hille CJ, Greenfield SA (2002) Functional domains in dorsal striatum of the nonhuman primate are defined by the dynamic behavior of dopamine. J Neurosci 22:5705-5712.

Cromwell HC, Hassani OK, Schultz W (2005) Relative reward processing in primate striatum. Exp Brain Res 162:520-525.

Everitt BJ, Robbins TW (2005) Neural systems of reinforcement for drug addiction: from actions to habits to compulsion. Nat Neurosci 8:1481-1489.

Eyny YS, Horvitz JC (2003) Opposing roles of $\mathrm{D}_{1}$ and $\mathrm{D}_{2}$ receptors in appetitive conditioning. J Neurosci 23:1584-1587.

Gauntlett-Gilbert J, Roberts RC, Brown VJ (1999) Mechanisms underlying attentional set-shifting in Parkinson's disease. Neuropsychologia 37:605-616.

Gerdeman GL, Partridge JG, Lupica CR, Lovinger DM (2003) It could be habit forming: drugs of abuse and striatal synaptic plasticity. Trends Neurosci 26:184-192.

Gerfen CR, Engber TM, Mahan LC, Susel Z, Chase TN, Monsma JFJ, Sibley DR (1990) D1 and D2 dopamine receptor-regulated gene expression of striatonigral and striatopallidal neurons. Science 250:1429-1432.

Glimcher PW (2001) Making choices: the neurophysiology of visualsaccadic decision making. Trends Neurosci 24:654-659.

Gonon F (1997) Prolonged and extrasynaptic excitatory action of dopamine mediated by $\mathrm{D}_{1}$ receptors in the rat striatum in vivo. J Neurosci 17:5972-5978.

Goto Y, Grace AA (2005) Dopaminergic modulation of limbic and cortical drive of nucleus accumbens in goal-directed behavior. Nat Neurosci 8:805-812.

Hayes AE, Davidson MC, Keele SW, Rafal RD (1998) Toward a functional analysis of the basal ganglia. J Cogn Neurosci 10:178-198.

Hikosaka O, Sakamoto M, Usui S (1989) Functional properties of monkey caudate neurons. I. Activities related to saccadic eye movements. J Neurophysiol 61:780-798.

Hikosaka O, Takikawa Y, Kawagoe R (2000) Role of the basal ganglia in the control of purposive saccadic eye movements. Physiol Rev 80:953-978. 
Ikeda T, Hikosaka O (2003) Reward-dependent gain and bias of visual responses in primate superior colliculus. Neuron 39:693-700.

Ikemoto S, Panksepp J (1999) The role of nucleus accumbens dopamine in motivated behavior: a unifying interpretation with special reference to reward-seeking. Brain Res Brain Res Rev 31:6-41.

Inoue M, Oomura Y, Aou S, Nishino H, Sikdar SK (1985) Reward related neuronal activity in monkey dorsolateral prefrontal cortex during feeding behavior. Brain Res 326:307-312.

Ito R, Dalley JW, Robbins TW, Everitt BJ (2002) Dopamine release in the dorsal striatum during cocaine-seeking behavior under the control of a drug-associated cue. J Neurosci 22:6247-6253.

Itoh H, Nakahara H, Hikosaka O, Kawagoe R, Takikawa Y, Aihara K (2003) Correlation of primate caudate neural activity and saccade parameters in reward-oriented behavior. J Neurophysiol 89:1774-1783.

Jiang H, Stein BE, McHaffie JG (2003) Opposing basal ganglia processes shape midbrain visuomotor activity bilaterally. Nature 423:982-986.

Kato M, Miyashita N, Hikosaka O, Matsumura M, Usui S, Kori A (1995) Eye movements in monkeys with local dopamine depletion in the caudate nucleus. I. Deficits in spontaneous saccades. J Neurosci 15:912-927.

Kawagoe R, Takikawa Y, Hikosaka O (1998) Expectation of reward modulates cognitive signals in the basal ganglia. Nat Neurosci 1:411-416.

Kawagoe R, Takikawa Y, Hikosaka O (2004) Reward-predicting activity of dopamine and caudate neurons-a possible mechanism of motivational control of saccadic eye movement. J Neurophysiol 91:1013-1024.

Kobayashi S, Lauwereyns J, Koizumi M, Sakagami M, Hikosaka O (2002) Influence of reward expectation on visuospatial processing in macaque lateral prefrontal cortex. J Neurophysiol 87:1488-1498.

Kori A, Miyashita N, Kato M, Hikosaka O, Usui S, Matsumura M (1995) Eye movements in monkeys with local dopamine depletion in the caudate nucleus. II. Deficits in voluntary saccades. J Neurosci 15:928-941.

Lauwereyns J, Takikawa Y, Kawagoe R, Kobayashi S, Koizumi M, Coe B, Sakagami M, Hikosaka O (2002a) Feature-based anticipation of cues that predict reward in monkey caudate nucleus. Neuron 33:463-473.

Lauwereyns J, Watanabe K, Coe B, Hikosaka O (2002b) A neural correlate of response bias in monkey caudate nucleus. Nature 418:413-417.

Lei W, Jiao Y, Del Mar N, Reiner A (2004) Evidence for differential cortical input to direct pathway versus indirect pathway striatal projection neurons in rats. J Neurosci 24:8289-8299.

Leon MI, Shadlen MN (1999) Effect of expected reward magnitude on the response of neurons in the dorsolateral prefrontal cortex of the macaque. Neuron 24:415-425.

Liu Z, Murray EA, Richmond BJ (2000) Learning motivational significance of visual cues for reward schedules requires rhinal cortex. Nat Neurosci 3:1307-1315.

Ljungberg T, Apicella P, Schultz W (1991) Responses of monkey midbrain dopamine neurons during delayed alternation performance. Brain Res 567:337-341.

Lovinger DM, Partridge JG, Tang KC (2003) Plastic control of striatal glutamatergic transmission by ensemble actions of several neurotransmitters and targets for drugs of abuse. Ann NY Acad Sci 1003:226-240.

Lynd-Balta E, Haber SN (1994) The organization of midbrain projections to the striatum in the primate: sensorimotor-related striatum versus ventral striatum. Neuroscience 59:625-640.

Mahon S, Deniau JM, Charpier S (2004) Corticostriatal plasticity: life after the depression. Trends Neurosci 27:460-467.

McClure SM, York MK, Montague PR (2004) The neural substrates of reward processing in humans: the modern role of fMRI. The Neuroscientist 10:260-268.

Miyashita N, Hikosaka O, Kato M (1995) Visual hemineglect induced by unilateral striatal dopamine deficiency in monkeys. NeuroReport 6:1257-1260.

Nicola SM, Surmeier J, Malenka RC (2000) Dopaminergic modulation of neuronal excitability in the striatum and nucleus accumbens. Annu Rev Neurosci 23:185-215.

Oades RD (1985) The role of noradrenaline in tuning and dopamine in switching between signals in the CNS. Neurosci Biobehav Rev 9:261-282.

Packard MG, Knowlton BJ (2002) Learning and memory functions of the Basal Ganglia. Annu Rev Neurosci 25:563-593.

Parthasarathy HB, Schall JD, Graybiel AM (1992) Distributed but convergent ordering of corticostriatal projections: analysis of the frontal eye field and the supplementary eye field in the macaque monkey. J Neurosci 12:4468-4488.
Paulus MP, Callaway CW, Geyer MA (1993) Quantitative assessment of the microstructure of rat behavior: II. Distinctive effects of dopamine releasers and uptake inhibitors. Psychopharmacology (Berl) 113:187-198.

Platt ML, Glimcher PW (1999) Neural correlates of decision variables in parietal cortex. Nature 400:233-238.

Reynolds JN, Wickens JR (2002) Dopamine-dependent plasticity of corticostriatal synapses. Neural Netw 15:507-521.

Robinson DA (1972) Eye movements evoked by collicular stimulation in the alert monkey. Vision Res 12:1795-1808.

Roesch MR, Olson CR (2004) Neuronal activity related to reward value and motivation in primate frontal cortex. Science 304:307-310.

Sato M, Hikosaka O (2002) Role of primate substantia nigra pars reticulata in reward-oriented saccadic eye movement. J Neurosci 22:2363-2373.

Satoh T, Nakai S, Sato T, Kimura M (2003) Correlated coding of motivation and outcome of decision by dopamine neurons. J Neurosci 23:9913-9923.

Schultz W (1998) Predictive reward signal of dopamine neurons. J Neurophysiol 80:1-27.

Schultz W, Tremblay L, Hollerman JR (2003) Changes in behavior-related neuronal activity in the striatum during learning. Trends Neurosci 26:321-328.

Selemon LD, Goldman-Rakic PS (1985) Longitudinal topography and interdigitation of corticostriatal projections in the rhesus monkey. J Neurosci 5:776-794.

Shidara M, Richmond BJ (2002) Anterior cingulate: single neuronal signals related to degree of reward expectancy. Science 296:1709-1711.

Stuphorn V, Taylor TL, Schall JD (2000) Performance monitoring by the supplementary eye field. Nature 408:857-860.

Sugrue LP, Corrado GS, Newsome WT (2004) Matching behavior and the representation of value in the parietal cortex. Science 304:1782-1787.

Surmeier DJ, Song WJ, Yan Z (1996) Coordinated expression of dopamine receptors in neostriatal medium spiny neurons. J Neurosci 16:6579-6591.

Takikawa Y, Kawagoe R, Hikosaka O (2002a) Reward-dependent spatial selectivity of anticipatory activity in monkey caudate neurons. J Neurophysiol 87:508-515.

Takikawa Y, Kawagoe R, Itoh H, Nakahara H, Hikosaka O (2002b) Modulation of saccadic eye movements by predicted reward outcome. Exp Brain Res 142:284-291.

Tran AH, Tamura R, Uwano T, Kobayashi T, Katsuki M, Ono T (2005) Dopamine D1 receptors involved in locomotor activity and accumbens neural responses to prediction of reward associated with place. Proc Natl Acad Sci USA 102:2117-2122.

Tulloch IF, Arbuthnott GW, Wright AK (1978) Topographical organization of the striatonigral pathway revealed by anterograde and retrograde neuroanatomical tracing techniques. J Anat 127:425-441.

van den Bos R, Cools AR (2003) Switching to cue-directed behavior: specific for ventral striatal dopamine but not ventral pallidum/substantia innominata gaba as revealed by a swimming-test procedure in rats. Neuroscience 118:1141-1149.

Vanderschuren LJ, Di Ciano P, Everitt BJ (2005) Involvement of the dorsal striatum in cue-controlled cocaine seeking. J Neurosci 25:8665-8670.

Watanabe K, Hikosaka O (2005) Immediate changes in anticipatory activity of caudate neurons associated with reversal of position-reward contingency. J Neurophysiol 94:1879-1887.

Watanabe K, Kimura M (1998) Dopamine receptor-mediated mechanisms involved in the expression of learned activity of primate striatal neurons. J Neurophysiol 79:2568-2580.

Watanabe K, Lauwereyns J, Hikosaka O (2003) Neural correlates of rewarded and unrewarded eye movements in the primate caudate nucleus. J Neurosci 23:10052-10057.

Watanabe M (1996) Reward expectancy in primate prefrontal neurons. Nature 382:629-632.

West AR, Grace AA (2002) Opposite influences of endogenous dopamine $\mathrm{D}_{1}$ and $\mathrm{D}_{2}$ receptor activation on activity states and electrophysiological properties of striatal neurons: studies combining in vivo intracellular recordings and reverse microdialysis. J Neurosci 22:294-304.

White NM, McDonald RJ (2002) Multiple parallel memory systems in the brain of the rat. Neurobiol Learn Mem 77:125-184.

Wise RA (2004) Dopamine, learning and motivation. Nat Rev Neurosci 5:483-494.

Yun IA, Wakabayashi KT, Fields HL, Nicola SM (2004) The ventral tegmental area is required for the behavioral and nucleus accumbens neuronal firing responses to incentive cues. J Neurosci 24:2923-2933. 